\title{
Drug agency accused of political bias
}

\section{WASHINGTON DC}

A top official at the US Food and Drug Administration (FDA) resigned last week in protest at the agency's failure to make a 'morning after' contraceptive more readily available. Her departure fuelled charges that the agency has surrendered its scientific independence to conservative pressure from the administration of President George W. Bush.

Susan Wood, who directed the FDA's Office of Women's Health, wrote in a 31 August e-mail to her colleagues: "I can no longer serve as staff when scientific and clinical evidence, fully evaluated and recommended for approval by the professional staff here, has been overruled"

Wood told Nature that the FDA's recent decision to delay making the 'morning after' pill Plan B (levonorgestrel) available over the counter bore the hallmarks of political interference. ${ }^{\alpha}$ It was very unusual for the commissioner of the FDA to essentially overrule the recommendation of all of the professional staff," she says.

The drug's manufacturer, Barr Pharmaceuticals in Woodcliff Lake, New Jersey, originally applied in 2003 to get Plan B's prescription-only status changed so that it would be available over the counter. The FDA rejected this in 2004, going against its own staff and an outside panel of expert advisers, who voted 23-4 in favour of

\section{IMAGE \\ UNAVAILABLE FOR COPYRIGHT REASONS}

Campaigners have found FDA delays over the 'morning after' pill Plan B hard to swallow.

the change. Barr then followed the FDA's advice by resubmitting the application, this time asking for the contraceptive to be available over the counter only to women over 16

A promised decision on that application was delayed late last month, when FDA commissioner Lester Crawford announced that Plan B presented "unique" regulatory obstacles.

Activists who believe that life begins at conception have vehemently opposed making access to the contraceptive easier. ${ }^{\alpha}$ Thank goodness there is now one less political activist at the FDA who puts radical feminist ideology above women's health," says Wendy Wright, senior policy director at Concerned Women for America, a conservative activist group in Washington DC.

Pressure has also come from the other side. Two Democrat senators this spring blocked Crawford's nomination as FDA commissioner until they were guaranteed a final decision on Plan B's over-the-counter availability by 1 September (see Nature 436, 442; 2005). The two senators, Hillary Clinton (New York) and Patty Murray (Washington), expressed outrage over the new delay, calling it "a breach of faith".

${ }^{\alpha}$ The president now has his FDA administrator, but the American public still does not have an answer on Plan B, they wrote in a letter on 30 August to Michael Leavitt, the Secretary of Health and Human Services.

In a similarly angry editorial, published online last week by The New England Journal of Medicine (doi:10.1056/NEJMp058222), editor-in-chief Jeffrey Drazen and others wrote that the FDA's actions have "made a mockery of the process of evaluating scientific evidence, disillusioned many of the participating scientists both inside and outside the agency [and] squandered the public trust." Meredith Wadman

\section{Poles lose out as ozone levels begin to recover}

There are mixed tidings for Earth's protective ozone layer this year. Although the seasonal Antarctic ozone hole has already swollen to the size of Europe, the ozone layer worldwide seems to be on the road to recovery.

Ozone molecules in the atmosphere shield Earth from harmful ultraviolet radiation, but man-made chemicals called chlorofluorocarbons (CFCs) eat away at the protective layer. Last week, the European Space Agency's Envisat satellite recorded an exceptionally large seasonal ozone hole forming over the South Pole (shown right in dark blue). Only the holes of 1996 and 2000 have been larger at this time of year.

But everywhere except the polar regions, the ozone layer seems to have stopped thinning as early as 1996, a study now suggests. CFC use was phased out by the 1987 Montreal Protocol, and researchershave been monitoring ozone levels for signs of recovery.
The latest study relies on a sophisticated regression analysis of ozone measurements from satellite- and groundbased instruments taken between 1978 and 2002 (G. C. Reinsel et al. J. Geophys. Res. 110, D16306, 2005). It found evidence for a modest but lasting ozone recovery, particularly at high latitudes.

"Our findingsdo offer hope," says Elizabeth Weatherhead, an environmental researcher at the University of Colorado at Boulder and one of the study's co-authors. "But we are still in a depleted state, and there has also been very little improvement in lessening of ultraviolet radiation since the mid-1990s."

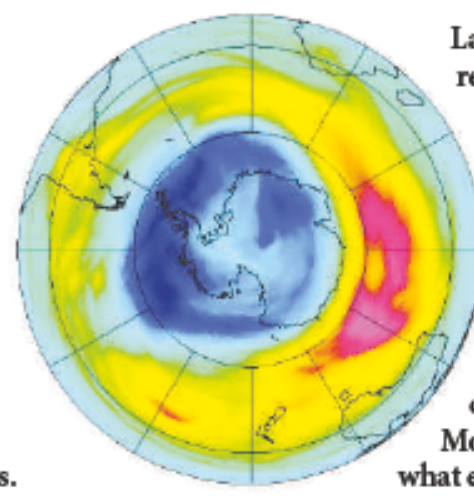

Last spring, scientists reported the biggest ozone losses ever recorded over the Arctic, probablydue to unusually low winter temperatures (see Nature 435, 6; 2005). Experts are divided as to whether the turnaround in ozone levels can be attributed to the Montreal Protocol, and if so to agree that because CFCs last for a long time in the atmosphere, ozone levels should have continued to fall until the end of the last century. Some scientists therefore argue that ifozone destruction peaked as early as 1996, other changes in atmospheric dynamics must also be at work.

Quirin Schiermeier 